\title{
Integrating acute malnutrition interventions into national health systems: lessons from Niger
}

\author{
Hedwig Deconinck ${ }^{1 *}$ (D), Mahaman Hallarou², Bart Criel ${ }^{3}$, Philippe Donnen² and Jean Macq ${ }^{1}$
}

\begin{abstract}
Background: Since 2007, integrated care of acute malnutrition has been promoted in Niger, a country affected by high burden of disease. This policy change aimed at strengthening capacity and ownership to manage the condition. Integration was neither defined nor planned but assumed to have been achieved. This paper studied the level and progress of integration of acute malnutrition interventions into key health system functions.

Methods: The qualitative study method involved literature searches on acute malnutrition interventions for children under 5 in low-income countries to develop a matrix of integration. Integration indicators defined three levels of integration of acute malnutrition interventions into health system functions-full, partial or none. Indicators of health services and health status were added to describe health system improvements. Data from qualitative and quantitative studies conducted in Niger between 2007 and 2013 were used to measure the indicators for the years under study.

Results: Results showed a mosaic of integration levels across key health system functions. Four indicators showed full integration, 22 showed partial integration and three showed no integration. Two-thirds of system functions showed progress in assimilating acute malnutrition interventions, while six persistently stagnated over time. There was variation within and across health system domains, with governance and health information functions scoring highest and financing lowest. Steady improvements were noted in geographic coverage, access and under-5 mortality risk.

Conclusions: This study provided useful information to inform policy makers and guide strategic planning to improve integration of acute malnutrition interventions in Niger. The proposed method of assessing the extent of integration and monitoring progress may be adapted and used in Niger and other low-income countries that are integrating or intending to integrate acute malnutrition interventions.
\end{abstract}

Keywords: Acute malnutrition, Integration, Indicators, Health system, Low-income countries, Niger

\section{Background}

During the emergency response to the 2005 food crisis, technical and financial partners of the Ministry of Public Health $(\mathrm{MOH})$ of Niger introduced a new approach to address acute malnutrition. This approach treated most children with the condition as outpatients in decentralised care rather than hospitalising them, and added active community case finding for early start of treatment. The demonstrated effectiveness and feasibility of the

\footnotetext{
* Correspondence: hedwig.deconinck@gmail.com

'Institut de recherche santé et société, Université catholique de Louvain, Clos

Chapelle-aux-Champs 30, Brussels 1200, Belgium

Full list of author information is available at the end of the article
}

new approach prompted the $\mathrm{MOH}$ to issue directives in 2007 for integrating acute malnutrition interventions into public health care. From then onward, partners no longer implemented acute malnutrition care but instead progressively provided support to the government for implementation. The policy change aimed at government ownership and scale-up the intervention by strengthening national and local capacity to improve access and coverage for the 1 million children under 5 years of age affected with acute malnutrition every year in Niger [1].

Despite the countrywide decentralisation of the management of acute malnutrition, less than one-third of all children with acute malnutrition were admitted for treatment 
in 2013 [2]. As in most low-income countries with a high burden of acute malnutrition, Niger's health system faced important operational capacity and resource challenges to delivering acute malnutrition interventions. Evaluations of acute malnutrition programmes conducted in low-income countries between 2007 and 2013 [3-5] identified challenges in systemic, organisational and clinical capacities for quality of care, integration and scale-up. With continuing high caseloads of acute malnutrition in Niger, time and again, questions about how to improve access and coverage of the integrated interventions surfaced. One systematic review studied the level of integration of health worker programmes into health systems [6], but no such studies on level of integration have been published on acute malnutrition. This paper assessed the level and trend of integration of acute malnutrition interventions in Niger since 2007. Factors that influenced the integration process were discussed in another paper. The results of the assessment may be useful to inform policy makers and guide strategic planning for improved acute malnutrition services.

\section{Methods}

We applied qualitative methods to study the status of integration of acute malnutrition interventions in Niger. For the purpose of this paper, integration was defined from a health system perspective as the extent, pattern and rate of adoption and assimilation of interventions for management of acute malnutrition into key functions of the national health system [7]. Integrated care of children with acute malnutrition and other illness was central to our study and viewed as a result of a process and activities undertaken at multiple levels of systemic, managerial, organisational, professional and clinical integration [8].

The study methods consisted of three distinct steps. First, we reviewed published and grey literature on acute malnutrition interventions and their integration into national health systems [9]. We then adapted a list of key health system functions for the integration of acute malnutrition interventions from a framework that had been used and validated in different countries [4, 9]. Functions were organised according to the six domains of the health system [10] (i.e. governance, health financing, health information, health workforce, medical products and service delivery). We then developed a diagnostic tool with 29 indicators to measure past and current integration of acute malnutrition interventions into the identified key health system functions. Guided by the literature $[6,7,11]$, we defined the integration indicators and their level of integration along a continuum (no interactions or segregation when no integration existed; linkage or coordination when partial integration existed; and full integration when health system functions and structures had assimilated or merged [12]). The diagnostic tool also included indicators for measuring the performance (geographic coverage, access to treatment, quality of care, contact coverage and sustainability) of acute malnutrition services and two indicators for measuring health status (prevalence of acute malnutrition and under-5 mortality). Indicators and their levels are described in the Additional file 1: Table S1. Second, we used data from qualitative and quantitative studies conducted in 2007 [13], 2010 [14] and 2013 [15] to measure integration and performance of acute malnutrition services and health outcome $[1,16-20]$ as proposed by the indicators. The qualitative studies reviewed health system capacity to implement and integrate acute malnutrition interventions in health districts in Niger between June 2007 and March 2014. The respective study teams, lead by the first author, visited national, regional and district hospitals, health centres, health posts and communities in seven out of eight regions (Diffa, Dosso, Maradi, Niamey, Tahoua, Tillabéry and Zinder). Data were collected through key informant interviews and semi-structured focus group discussions with government administrators and partners at national, regional, district and community level, district health managers and health workers, community volunteers and members and service users. Level-adapted questionnaires with open-ended questions were developed and tested before use. The working language was French, and simultaneous translation was available for discussions in the local languages. Findings were recorded on paper, summarized in a spreadsheet, analysed by theme, triangulated and summarized [13-15]. In addition, relevant policies, implementation strategies, guidelines and annual action plans at national, regional and district levels, as well as national, regional and district databases were consulted to assess the quality of planning and performance of service delivery. Third, participation in national coordination meetings and planning workshops allowed triangulation and validation of the proposed indicators definitions and levels and their results.

\section{Results and discussion}

This qualitative study assessed the level of integration of acute malnutrition interventions into key health system functions in Niger and mapped the progress of integration for 2007, 2010 and 2013 (Table 1). Results showed a mosaic of integration levels across health system functions. Four indicators showed full integration, 21 showed partial integration and three showed no integration. Two-thirds of system functions showed progress in assimilating acute malnutrition interventions, and six persistently stagnated over time. There was variation within and across domains. Governance and health information system functions scored best, and health financing scored worst. The acute malnutrition services indicators of geographic coverage and access to treatment improved, the indicator of quality of care was adequate and stable, and the indicators of contact 
Table 1 Integration level of acute malnutrition interventions and health outcome in Niger

\begin{tabular}{|c|c|c|c|c|}
\hline Elements & Indicator & 2007 & 2010 & 2013 \\
\hline \multicolumn{5}{|l|}{ Health system functions } \\
\hline \multicolumn{5}{|l|}{ Governance } \\
\hline Policy setting & $\begin{array}{l}\text { National health and nutrition policies with the integrated management } \\
\text { of acute malnutrition (IMAM) as part of child health care (i.e. integrated } \\
\text { management of childhood illness (IMCI) and child hospital care) }\end{array}$ & No & Partial & Full \\
\hline National guidelines & National guidelines for IMAM supporting comprehensive child health care & No & Partial & Full \\
\hline Technical leadership & A technical advisory group for comprehensive child health care & Partial & Partial & Partial \\
\hline Regulation and coordination & $\begin{array}{l}\text { Regulation and coordination of health actors (including financial and technical } \\
\text { partners, education and training institutions, professional associations, private } \\
\text { and informal health sector, communities and champions) aligning with the } \\
\text { national health and nutrition policy and implementation strategy }\end{array}$ & Partial & Partial & Partial \\
\hline Social participation & $\begin{array}{l}\text { Social participation of local and community actors in planning, implementing } \\
\text { and monitoring child health care with a people-centred care approach }\end{array}$ & No & No & No \\
\hline \multicolumn{5}{|l|}{ Health financing } \\
\hline $\begin{array}{l}\text { Regular budget-pooled } \\
\text { funding }\end{array}$ & $\begin{array}{l}\text { Regular budget from pooled funds with a sector-wide approach covering } \\
\text { financing for IMAM }\end{array}$ & No & No & Partial \\
\hline Annual costed action plans & Annual costed action plans of $\mathrm{MOH}$ covering IMAM interventions & No & No & Partial \\
\hline Health workers payroll & Staff in national health facilities involved in IMAM on $\mathrm{MOH}$ payroll & No & No & Partial \\
\hline Financial risk protection & $\begin{array}{l}\text { Fee waiver system for children under } 5 \text { covering comprehensive child health } \\
\text { care }\end{array}$ & No & Partial & Partial \\
\hline \multicolumn{5}{|l|}{ Health information } \\
\hline $\begin{array}{l}\text { Health information system } \\
\text { (HIS) }\end{array}$ & National HIS, including acute malnutrition indicators & No & Partial & Full \\
\hline $\begin{array}{l}\text { Performance monitoring } \\
\text { system }\end{array}$ & Performance monitoring of comprehensive child health care & No & Partial & Full \\
\hline Contact coverage monitoring & IMAM coverage monitoring as part of child health care coverage monitoring & No & No & No \\
\hline \multicolumn{5}{|l|}{ Health workforce } \\
\hline $\begin{array}{l}\text { Adequate coverage of } \\
\text { health workers }\end{array}$ & $\begin{array}{l}\text { Adequate number of qualified health workers with geographic coverage for } \\
\text { comprehensive child health care }\end{array}$ & No & Partial & Partial \\
\hline $\begin{array}{l}\text { Competences of health } \\
\text { managers and health workers }\end{array}$ & $\begin{array}{l}\text { Adequate technical and organizational management skills for comprehensive } \\
\text { child health care }\end{array}$ & Partial & Partial & Partial \\
\hline $\begin{array}{l}\text { Performance appraisal and } \\
\text { motivation system }\end{array}$ & $\begin{array}{l}\text { Performance appraisal and career development opportunities as part of the } \\
\text { human resources management system }\end{array}$ & No & Partial & Partial \\
\hline Pre-service education & $\begin{array}{l}\text { Modules of pre-service education curriculum on comprehensive child health } \\
\text { and nutrition }\end{array}$ & No & Partial & Partial \\
\hline $\begin{array}{l}\text { Continuing professional } \\
\text { development }\end{array}$ & $\begin{array}{l}\text { Continuing professional development on comprehensive child health and } \\
\text { nutrition }\end{array}$ & No & Partial & Partial \\
\hline \multicolumn{5}{|l|}{ Medical products } \\
\hline $\begin{array}{l}\text { Essential medicines and } \\
\text { medical supplies list }\end{array}$ & National essential drugs and medical supplies list, including for IMAM & No & Partial & Partial \\
\hline Procurement system & $\begin{array}{l}\text { National drugs and medical supply needs (forecasting and) procurement } \\
\text { including for IMAM }\end{array}$ & No & No & Partial \\
\hline Logistic management system & $\begin{array}{l}\text { National logistic management system for drugs and medical supplies } \\
\text { including for IMAM }\end{array}$ & No & Partial & Partial \\
\hline \multicolumn{5}{|l|}{ Service delivery } \\
\hline Demand generation & $\begin{array}{l}\text { Demand generation by activating and informing communities for improved } \\
\text { child health and nutrition }\end{array}$ & No & No & No \\
\hline Early case finding & $\begin{array}{l}\text { Early active (by volunteers in the community), systematic (by health workers } \\
\text { at the health facility) and enhanced (by carer) case finding for selected } \\
\text { child illnesses }\end{array}$ & No & Partial & Partial \\
\hline $\begin{array}{l}\text { Community-based } \\
\text { primary care }\end{array}$ & $\begin{array}{l}\text { Promotive and preventive community health and nutrition (and community } \\
\text { case management) }\end{array}$ & No & Partial & Partial \\
\hline
\end{tabular}


Table 1 Integration level of acute malnutrition interventions and health outcome in Niger (Continued)

\begin{tabular}{|c|c|c|c|c|}
\hline $\begin{array}{l}\text { Outpatient care (facility-based } \\
\text { primary care) }\end{array}$ & $\begin{array}{l}\text { Outpatient management of severe acute malnutrition (SAM) without } \\
\text { complications and moderate acute malnutrition (MAM) as part of IMCI }\end{array}$ & No & Partial & Partial \\
\hline $\begin{array}{l}\text { Inpatient care (child hospital } \\
\text { care) }\end{array}$ & $\begin{array}{l}\text { Inpatient management of SAM with complications until stabilisation as } \\
\text { part of child hospital care }\end{array}$ & No & Partial & Partial \\
\hline Health outreach & $\begin{array}{l}\text { Health outreach activities for selected child illnesses, including acute } \\
\text { malnutrition }\end{array}$ & No & Partial & Partial \\
\hline $\begin{array}{l}\text { Referral and tracing between } \\
\text { services }\end{array}$ & $\begin{array}{l}\text { Referral and tracing system for detection and retention in treatment } \\
\text { of selected child illnesses, including acute malnutrition }\end{array}$ & No & Partial & Partial \\
\hline $\begin{array}{l}\text { Patient-centred continuity of } \\
\text { care }\end{array}$ & $\begin{array}{l}\text { Comprehensive child health care tracked over time and place } \\
\text { responding to individual preferences, needs and values }\end{array}$ & No & No & Partial \\
\hline $\begin{array}{l}\text { Continuous quality } \\
\text { improvement }\end{array}$ & Continuous quality improvement of comprehensive child health care & No & Partial & Partial \\
\hline \multicolumn{5}{|l|}{ Health services performance } \\
\hline \multirow[t]{4}{*}{ Geographic service coverage } & Number of sites with SAM services & \multirow{2}{*}{$\begin{array}{l}30[13] \\
(<5 \%)\end{array}$} & \multirow{2}{*}{$\begin{array}{l}772[26] \\
(>70 \%)\end{array}$} & \multirow{2}{*}{$\begin{array}{l}944[15] \\
(>95 \%)\end{array}$} \\
\hline & (Proportion (\%) of primary health facilities offering SAM services) & & & \\
\hline & Number of sites with MAM services & \multirow{2}{*}{$\begin{array}{l}610[13] \\
(<5 \%)\end{array}$} & \multirow{2}{*}{$\begin{array}{l}850[26] \\
(>75 \%)\end{array}$} & \multirow{2}{*}{$\begin{array}{l}1180[15] \\
(>95 \%)\end{array}$} \\
\hline & (Proportion (\%) of primary health facilities offering MAM services) & & & \\
\hline \multirow[t]{2}{*}{ Access to treatment } & Annual number of children under 5 accessing treatment for SAM & $\begin{array}{l}60843 \\
{[13]}\end{array}$ & $\begin{array}{l}330000 \\
{[26]}\end{array}$ & $\begin{array}{l}406327 \\
{[15]}\end{array}$ \\
\hline & Annual number of children under 5 accessing treatment for MAM & $\begin{array}{l}275030 \\
{[13]}\end{array}$ & $\begin{array}{l}257000 \\
{[26]}\end{array}$ & $\begin{array}{l}520398 \\
{[15]}\end{array}$ \\
\hline \multirow[t]{2}{*}{ Quality of care } & Annual overall SAM cure, case-fatality and defaulting rates & Good [13] & Good [26] & Good [15] \\
\hline & Annual overall MAM cure, case-fatality and defaulting rates & Good [13] & Good [26] & Good [15] \\
\hline Contact coverage & $\begin{array}{l}\text { Proportion of children under } 5 \text { diagnosed with SAM in the population } \\
\text { receiving treatment }\end{array}$ & Low [13] & Low [27] & Low [15] \\
\hline \multirow[t]{2}{*}{ Sustainability } & $\begin{array}{l}\text { Sustainability based on financial and technical dependence of IMAM } \\
\text { interventions }\end{array}$ & \multirow[t]{2}{*}{$\begin{array}{l}\text { Low }[13] \\
\text { (NA) }\end{array}$} & \multirow[t]{2}{*}{$\begin{array}{l}\text { Low }[14] \\
(41 \% ; 13)\end{array}$} & \multirow[t]{2}{*}{$\begin{array}{l}\text { Low }[15] \\
(60 \% ; 20)\end{array}$} \\
\hline & $\begin{array}{l}\text { (Proportion (\%) of primary health facilities with IMAM services receiving } \\
\text { technical partner support; number of technical partners) }\end{array}$ & & & \\
\hline \multicolumn{5}{|l|}{ Health status } \\
\hline \multirow[t]{2}{*}{$\begin{array}{l}\text { Prevalence of acute } \\
\text { malnutrition }\end{array}$} & $\begin{array}{l}\text { Proportion (\%) of children under } 5 \text { diagnosed with SAM in the population } \\
\text { (confidence interval) }\end{array}$ & $\begin{array}{l}0.8 \%[19] \\
(\mathrm{NA})\end{array}$ & $\begin{array}{l}3.2 \%[17] \\
(2.7-3.7)\end{array}$ & $\begin{array}{l}2.6 \%[1] \\
(2.2-3.1)\end{array}$ \\
\hline & $\begin{array}{l}\text { Proportion (\%) of children under } 5 \text { diagnosed with overall acute malnutrition } \\
\text { in the population (confidence interval) }\end{array}$ & $\begin{array}{l}11.0 \% \\
{[19](N A)}\end{array}$ & $\begin{array}{l}15.5 \%[17] \\
(14.2-16.8)\end{array}$ & $\begin{array}{l}13.3 \%[1] \\
(12.3-14.3)\end{array}$ \\
\hline \multirow[t]{2}{*}{ Under-5 mortality } & Probability of dying before 5 years of age expressed per 1000 live births & $\begin{array}{l}230[19] \\
(217-244)\end{array}$ & NA & $\begin{array}{l}127[18] \\
(119-136)\end{array}$ \\
\hline & $\begin{array}{l}\text { Proportion of deaths of children under } 5 \text { in the population per } 10000 \\
\text { children per day (confidence interval) }\end{array}$ & $\begin{array}{l}1.8[20] \\
(\mathrm{NA})\end{array}$ & $\begin{array}{l}2.1[17] \\
(N A)\end{array}$ & $0.7[1](N A)$ \\
\hline
\end{tabular}

IMAM: Integrated Management of Acute Malnutrition; IMCI: Integrated Management of Childhood Illness; NA: not available; MAM: Moderate Acute Malnutrition; $\mathrm{MOH}$ : Ministry of Public Health; SAM: Severe Acute Malnutrition

coverage and sustainability remained low. The health status indicator of acute malnutrition prevalence was unstable for the years under study but showed improvement for 2013, and of under- 5 mortality risk showed improvement for 2013.

The study findings that integration of acute malnutrition interventions were only partially achieved contrasted with the general perception in Niger that the management of acute malnutrition was integrated into the national health system. The following sections discuss what integrated management of acute malnutrition meant in Niger, what was expected of it and what can be learned from it.

\section{Understanding integration and its aim}

Since the Niger $\mathrm{MOH}$ called for the provision of integrated management of acute malnutrition (IMAM) -Prise en charge intégrée de la malnutrition aiguë- as a routine health service in all public health facilities in 2007, it assumed instant integration. Integration initially was interpreted from an organisational perspective as care provided by the public health sector in all health facilities. With 
time, it evolved to mean integrated care of patients from a clinical perspective. The question of what "integrated care" means, or what dimension of integration is being addressed is common [8], and not just for Niger or the management of acute malnutrition. Integrative functions of primary care include dimensions of systemic, managerial, organisational and professional integration at the meso and macro level of population-based care that is needed to obtain clinical integration of patientfocused care at the micro level. Both functional and normative integration are integrative functions that cut across the different levels of care [12]). For Niger, the use of a clear taxonomy of integrative functions of care would contribute to the understanding of the complex and multi-dimensional nature of integrated care as a process and hence its improvement [8].

The quest of the $\mathrm{MOH}$ to integrate management of acute malnutrition was driven by its taking ownership of improving coordinated care as well as other assumptions. First, integration would rapidly scale up service delivery. Second, integration would resolve capacity concerns at national, regional and local governance and implementation levels. Third, integration would resolve all other concerns about quality of care, inequitable coverage, unbalanced resource allocations, and uncertain financial and institutional sustainability. A general belief associates integration of health services with improved efficiency, cost-effectiveness, client-orientation, equity, local ownership, quality and health status overall [21]. However, systematic reviews of integration of primary health care in low-income countries were unable to draw conclusions on the benefits and disadvantages of integrated services [21-23]. These studies have at least two relevant lessons for Niger. First, integrating a service does not necessarily mean integrating all of its components, as permutations are possible. Second, integration is not a cure for inadequate resources or capacities. For Niger, evidence of the effectiveness of integrative functions for improved acute malnutrition services and health outcome would inform appropriate strategy designs adapted to the country-context and the capacities of the $\mathrm{MOH}$ and its partners.

\section{Learning from the integration process}

The mosaic pattern of integration of acute malnutrition interventions (Table 1) indicated a complex and dynamic process, or continuum [24] that showed gradual progress. The absence of a strategy or phased plan implied that integration resulted from a natural self-organisation rather than orderly planning. It also showed that achieving integrated care of children with acute malnutrition required changes not only in service delivery, but also in systemic and organizational dimensions of care. Furthermore, it showed that integration into key system functions did not progress simultaneously and therefore may not always be desirable, possible or opportune.

We identified two consequences of the failure to translate the 2007 policy on integrated management of acute malnutrition into an adapted implementation strategy. First, the policy set no goals for what aspects or components of acute malnutrition interventions to integrate how, when, why or where. Nor did it reflect on opportunities for and threats to integrated care of acute malnutrition or other health interventions. Because of the lack of a specific integration plan for IMAM in Niger, progress was not monitored and adverse or unintended effects on the health system were not studied or corrected. Positive effects of integration could have included extended coverage of interventions and increased capacity of the health system. Negative effects of integration could have included the removal of privileged status and the necessary pampering for maturation or the imbalanced care of public health priorities [25]. Second, the policy missed aligning health actors behind a common goal. As such, partners provided short-term support that yielded immediate results but did not collaboratively strengthen the health system with a long-term vision to adopt and assimilate integrated quality services sustainably. However, the policy was successful in the sense that partners gradually moved from direct implementation toward support for service delivery, which stimulated national and local ownership and political will and hence strengthened donor trust.

For Niger, an integration strategy for the management of acute malnutrition should set goals based on overall public health priorities and available capacities and resources. It should decide what aspects of interventions to integrate or not, and what aspects to outsource in the short or long term through, for example, public-private partnerships that are well regulated and coordinated as part of the same transformative change agenda. In some areas partners were well represented in the community and therefore well placed to implement the communitybased interventions. Some partners were well placed to distribute bulky supplies to the periphery. Task sharing could be effective under an overarching and collaborative strategic plan with a defined goal and oversight from the $\mathrm{MOH}$ to regulate and coordinate activities.

The integration matrix proved useful to map the level of integration of IMAM into key system functions and show progress over time. In our study, the matrix was itself the outcome of a diagnostic of key heath system functions, but it should ideally be linked with an implementation strategy to be able to measure and interpret progress and inform policy adaptations. The proposed indicators matrix is therefore a diagnostic tool that itself may be used to inform strategies and formulate objectives for improved integrated care. It therefore needs to be adapted or changed depending on the changing 
country context, implementation strategy and level of integrative functions under study. We anticipate that lessons from this case study may inform the integration strategy of the multisectoral interventions of the national nutrition security policy under development in Niger.

The study had important limitations. Information was collected at three intervals. A separate paper investigated factors that influenced the process of integration of acute malnutrition interventions in Niger and complements the interpretation of the results presented here. Moreover, in the absence of a national strategy for integrating acute malnutrition interventions, progress could not be compared to national goals. Without knowing what to aim at, the pattern of integration as shown in the results matrix has limited use. The integration indicators are measured from a systemic perspective but mix types of integration (e.g. organisational, functional, professional) and levels of health system targeted (e.g. micro, meso, macro). Furthermore, the study was not designed to measure the effect of integration of acute malnutrition interventions on the overall health system, but we added indicators of performance of acute malnutrition services and health outcome to understand the context in which the integration process occurred. Nevertheless, we missed information on cost of a treatment, equity, extra-budgetary financial contributions or donor investments that played a role in improved quality and sustainability.

\section{Conclusions}

The study developed and measured indicators to investigate the level and trend of integration of acute malnutrition interventions into key health system functions in Niger. The tool was able to assess the status and monitor the process of integration. The study uncovered the missed opportunity of a national integration strategy for integration of acute malnutrition interventions with clear goals and expectations that unlock local capacities and regulate partnerships for improved integrated care and sustainability.

We recommend that for future use, health actors consultatively and collaboratively adapt the indicator matrix to the integration strategy that is aligned with national health and nutrition policies and development plans and level of use. The proposed method of assessing and monitoring integration progress may be used in Niger and other countries to stimulate the debate of integrated care, and to improve strategic planning for improved health outcomes.

\section{Additional file}

Additional file 1: Table S1. Indicators of integration level of acute malnutrition interventions and health outcome. (DOC $121 \mathrm{~kb}$ )

\section{Abbreviations}

HIS: health information system; IMAM: integrated management of acute malnutrition; IMCl: integrated management of childhood illness;

MAM: moderate acute malnutrition; MCH: maternal and child health;

MOH: Ministry of Public Health; SAM: severe acute malnutrition.

\section{Competing interests}

The authors declare that they have no competing interests.

\section{Authors' contributions}

$\mathrm{HD}$ and JM contributed to the study design and data collection, analysis and synthesis. $\mathrm{MH}, \mathrm{BC}$ and PD contributed to the analysis and synthesis. $\mathrm{HD}$ drafted the manuscript. All authors revised the draft, and read and approved the final manuscript.

\section{Acknowledgements}

This paper is based on reviews made possible by FHI 360 and Save the Children Niger, which supported field visits and collection of the data presented in this paper. The authors would like to thank all the people in Niger who willingly spent time with us during visits. We would also like to acknowledge the support of successive directors of the Nutrition Directorate of the Ministry of Public Health during the reviews.

\section{Author details}

${ }^{1}$ Institut de recherche santé et société, Université catholique de Louvain, Clos Chapelle-aux-Champs 30, Brussels 1200, Belgium. ${ }^{2}$ Ecole de santé publique, Université libre de Bruxelles, route de Lennik 808, Brussels 1070, Belgium.

${ }^{3}$ Institute of Tropical Medicine, 155 Nationalestraat, Antwerp 2000, Belgium.

Received: 31 October 2015 Accepted: 22 February 2016

Published online: 10 March 2016

\section{References}

1. Institut national de la statistique (INS) du Niger. Rapport de l'enquete nutritionnelle et de la survie des enfants de 6 à 59 mois, 2013. Niamey: INS; 2013.

2. United Nations Children's Fund. Scaling Up Week 52, 2013. Niamey: UNICEF; 2013.

3. Deconinck H, Swindale A, Grant F, Navarro-Colorado C. Review of community-based management of acute malnutrition in the postemergency context: synthesis of lessons on integration of CMAM into national health systems in Ethiopia, Malawi and Niger. Washington: FANTA AED; 2008.

4. Deconinck H, Bahwere P, Diene S, de Bernardo D, Adou P. Review of community-based management of acute malnutrition implementation in West Africa: summary report. Washington: FANTA AED; 2011.

5. United Nations Children's Fund. Evaluation of community management of acute malnutrition: Global synthesis report. New York: UNICEF; 2013.

6. Zulu JM, Kinsman J, Michelo C, Hurtig A-K. Integrating national communitybased health worker programmes into health systems: a systematic review identifying lessons learned from low-and middle-income countries. BMC Public Health. 2014;14(1):987.

7. Atun R, de Jongh T, Secci F, Ohiri K, Adeyi O. Integration of targeted health interventions into health systems: a conceptual framework for analysis. Health Policy Plan. 2010;25(2):104-11.

8. Goodwin N. Understanding integrated care: a complex process, a fundamental principle. Int J Integr Care. 2013;13.

9. Deconinck H, De Man J, Macq J. Health systems strengthening for integrating and scaling up management of severe acute malnutrition. Report of a literature review. Brussels: Université catholique de Louvain; 2015.

10. World Health Organization. Everybody's business. Strengthening health systems to improve health outcomes. WHO's framework for action. Geneva: WHO; 2007.

11. Shigayeva A, Atun R, McKee M, Coker R. Health systems, communicable diseases and integration. Health Policy Plan. 2010;25 suppl 1:i4-i20.

12. Valentijn PP, Schepman SM, Opheij W, Bruijnzeels MA. Understanding integrated care: a comprehensive conceptual framework based on the integrative functions of primary care. Int J Integr Care. 2013;13.

13. Deconinck H, Grant F, Navarro-Colorado C. Review of integration of community-based management of acute malnutrition services in Niger. Washington: FANTA AED; 2007. 
14. Deconinck H, Bahwere P, Adou P. Review of community-based management of acute malnutrition in Niger. Washington: FANTA AED; 2011.

15. Deconinck $\mathrm{H}$. Review of integrated management of acute malnutrition in children in Niger. Niamey: Save the Children Niger; 2014.

16. Institut national de la statistique (INS) du Niger. Rapport de l'enquete nutritionnelle et de la survie des enfants de 6 à 59 mois, 2011. Niamey: INS; 2011.

17. Institut national de la statistique (INS) du Niger. Rapport de l'enquete nutritionnelle et de la survie des enfants de 6 à 59 mois, 2010. Niamey: INS; 2010.

18. Institut national de la statistique (INS) du Niger. Enquête démographique et de santé et à indicateurs multiples 2012 (EDNS-MICS IV). Niamey: INS; 2013.

19. Institut national de la statistique (INS) du Niger. Enquête démographique et de santé et à indicateurs multiples 2006 (EDNS-MICS III). Niamey: INS; 2006.

20. Institut national de la statistique (INS) du Niger. Rapport de l'enquete nutritionnelle et de la survie des enfants de 6 à 59 mois, 2007. Niamey: INS; 2007.

21. Briggs CJ, Capdegelle P, Garner P. Strategies for integrating primary health services in middle- and low-income countries: effects on performance, costs and patient outcomes. The Cochrane Database of Systematic Reviews 2001, Issue 4. Art. No.: CD003318. doi:10.1002/14651858.CD003318.

22. Atun R, de Jongh T, Secci F, Ohiri K, Adeyi O. A systematic review of the evidence on integration of targeted health interventions into health systems. Health Policy Plan. 2010;25(1):1-14.

23. Dudley L, Garner P. Strategies for integrating primary health services in lowand middle-income countries at the point of delivery. Cochrane Database of Systematic Reviews 2011, Issue 7. Art. No.: CD003318. doi:10.1002/ 14651858.CD003318.pub3

24. World Health Organization. Integrated health service. What and why? Technical brief 1. Geneva: WHO; 2008.

25. Criel B, Kegels $G$, Van der Stuyft P. Editorial: A framework for analysing the relationship between disease control programmes and basic health care. Tropical Med Int Health. 2004;9(6):A1-4.

26. Guero H, Doudou M, Chegou Y, Ategbo E-A. Management of acute malnutrition in Niger: a countrywide programme. Government experiences of CMAM scale up. Field Exch. 2012;43:51.

27. Johnston R. Programme data and coverage surveys: challenges to improve programming. What We Know Now: a Decade of Community-based Treatment of Severe Acute Malnutrition; October 18, 2013; London: CMN; 2013.

\section{Submit your next manuscript to BioMed Central and we will help you at every step:}

- We accept pre-submission inquiries

- Our selector tool helps you to find the most relevant journal

- We provide round the clock customer support

- Convenient online submission

- Thorough peer review

- Inclusion in PubMed and all major indexing services

- Maximum visibility for your research

Submit your manuscript at www.biomedcentral.com/submit

) Biomed Central 